BMJ Open

Diabetes

Research

\& Care

\section{Individuals at high risk for type 2 diabetes invited to a lifestyle program: characteristics of participants versus non-participants (the HUNT Study) and 24-month follow-up of participants (the VEND-RISK Study)}

To cite: Følling IS, Kulseng B, Midthjell $\mathrm{K}$, et al. Individuals at high risk for type 2 diabetes invited to a lifestyle program: characteristics of participants versus non-participants (the HUNT Study) and 24-month follow-up of participants (the VEND-RISK Study). BMJ Open Diab Res Care 2017;5:e000368. doi:10.1136/ bmjdrc-2016-000368

Received 25 November 2016 Revised 1 June 2017 Accepted 24 June 2017

\section{(a) CrossMark}

For numbered affiliations see end of article.

Correspondence to Ingrid Sørdal Følling; ingfoll@gmail.com

\section{ABSTRACT}

Objective Prevention of type 2 diabetes mellitus is possible through lifestyle programs, but the effect depends on the program's content, resources, and setting. Lifestyle programs are often confronted with high rates of non-participation and attrition. This study invited individuals at high risk for type 2 diabetes to a lifestyle program in the Norwegian primary healthcare setting. The aims were to investigate possible differences in characteristics between participants and nonparticipants and to study the effect of the lifestyle program at 24-month follow-up for participants.

Research design and methods Individuals identified at high risk for type 2 diabetes during the third survey of the Nord-Trøndelag Health Study (HUNT3) from two municipalities $(\mathrm{n}=332)$ were invited to a lifestyle program (the VEND-RISK Study). A cross-sectional design was used to explore if the participants' characteristics differed from non-participants. A non-randomized, single-arm, pre-post examination was used to examine the effect of the lifestyle program on participants' characteristics at 24-month follow-up.

Results of all individuals at high risk for type 2 diabetes invited to the lifestyle program, 86\% (287/332) declined to participate. Non-participating women had fewer years of education $(p<0.001)$, compared with participating women. For men, no differences were seen between non-participants and participants. Among all participants $(\mathrm{n}=45)$ at 24 -month follow-up, none had developed type 2 diabetes, and $\mathrm{HbA}$. $(p<0.001)$ had decreased significantly. There was a small reduction in mean body mass index from baseline to 24 months that was not statistically significant. For women, waist circumference $(-4.0 \mathrm{~cm}, \mathrm{p}<0.001)$ decreased significantly. Conclusions Future research regarding individuals at high risk for type 2 diabetes in the primary healthcare lifestyle program should focus on how to promote recruitment of women with low education. Participants attending this study's lifestyle program improved their cardiometabolic markers. Clinical trials registration NCT01135901; Results.

\section{INTRODUCTION}

The global type 2 diabetes epidemic will overwhelm healthcare resources if preventive

\section{Significance of the study}

What is already known about this subject? It has been shown that lifestyle programs in primary healthcare settings can prevent or delay the onset of type 2 diabetes for individuals at high risk for type 2 diabetes. However, lifestyle programs are often confronted with high non-participant rates and high level of attrition.

\section{What are the new findings?}

Women who declined to participate in a lifestyle program in the Norwegian primary healthcare setting had fewer years of education, compared with women who participated. For men, no differences were seen among non-participants and participants. Among participants at high risk of type 2 diabetes at 24-month follow-up, none developed type 2 diabetes, and $\mathrm{HbA}$. $(p<0.001)$ decreased significantly. Body mass index decreased slightly, but not significantly, among all participants (from 30.2 at baseline to $29.7 \mathrm{~kg} / \mathrm{m}^{2}$ at 24-month follow-up). For women, waist circumference $(-4.0 \mathrm{~cm}, \mathrm{p}<0.001)$ decreased significantly.

How might these results change the focus of research or clinical practice?

Based on these results, to prevent type 2 diabetes using the Norwegian primary healthcare system, lifestyle programs for individuals at high risk for type 2 diabetes could focus on how to promote recruitment of women with low education. The results further highlights the importance of maintenance of lifestyle change for older adults at high risk for type 2 diabetes.

strategies are not urgently implemented. ${ }^{1}$ The number of people with type 2 diabetes is also increasing in Norway. ${ }^{2}$ The importance of preventing type 2 diabetes has been highlighted over the last 10 years, ${ }^{3}$ and several studies have shown that type 2 diabetes can be 
prevented when individuals at high risk make changes in diet and physical activity habits. ${ }^{46}$ The Norwegian Health Authorities have recommended that all municipalities establish lifestyle programs at Healthy Life Centres as part of the primary healthcare system to serve individuals who need to make changes in diet, physical activity and tobacco use. $^{78}$

Unfortunately, lifestyle programs are often confronted with low participation rates and high level of attrition. ${ }^{9}$ The individuals who choose not to participate in lifestyle programs might be those who would have benefitted most from the programs offered..$^{10}$ Reasons given from potential participants for not participating in lifestyle programs are usually health related. ${ }^{11}$ However, in studies, it is found that non-participants are more likely to live in rural areas, ${ }^{12}$ have a lower level of education, ${ }^{1315}$ lower socioeconomic status and are more often men. ${ }^{13} 1416$ Women are more likely than men to have contact with the healthcare system. ${ }^{17}$ In addition, women are at higher residual lifetime risk for type 2 diabetes than men. ${ }^{18}$ The characteristics of women and men choosing or declining to participate in lifestyle programs could somehow differ. Identifying the characteristics of women and men who decline to participate in a lifestyle program can add useful knowledge about where efforts should be targeted to recruit both women and men to lifestyle programs to prevent type 2 diabetes.

The Finnish Diabetes Prevention Study (DPS), the US Diabetes Prevention Program (DPP) and the China Da Qing Diabetes Prevention Study showed that type 2 diabetes can be prevented when individuals at high risk make lifestyle changes when conducted in comprehensive experimental settings. ${ }^{46}$ However, there are questions concerning how best to translate knowledge from comprehensive experimental settings to local primary healthcare settings. ${ }^{19}$ Studies that have transferred the interventions on preventing type 2 diabetes from experimental settings to local primary healthcare settings have shown successful results, assuming that it is possible to prevent type 2 diabetes in local primary healthcare settings. ${ }^{1922}$ However, the content of each lifestyle program depends on the resources in the local primary healthcare system where the program is offered. There has been a call to replicate long-term studies in primary healthcare settings to examine the feasibility of lifestyle programs and the resources and level of intensity they require to prevent type 2 diabetes. ${ }^{23}$ In Norway, there has been a demand for documentation of the long-term effect of lifestyle programs in preventing type 2 diabetes in primary healthcare settings, such as municipal Healthy Life Centre.

This studys first aim was to investigate if the characteristics of women and men at high risk for type 2 diabetes who chose to participate in a lifestyle program (the VEND-RISK Study) differed from those who declined to participate. The second aim was to study the effect of a 12-month lifestyle program in the Norwegian primary healthcare service for participants at high risk for type
2 diabetes at 24-month follow-up. The primary outcome was to examine 24 months changes in glycemic measures and cardiometabolic markers. The secondary outcome was to see if overweight and obesity were reduced and if participants cardiometabolic profile changed.

\section{RESEARCH DESIGN AND METHODS \\ Study design and settings}

A cross-sectional design was used to explore if the characteristics of those at high risk for type 2 diabetes but who declined to participate after being invited to a lifestyle program (the VEND-RISK Study) differed from those who participated. A non-randomized, single-arm, prepost examination was used to investigate the effect on cardiometabolic changes among participants in the lifestyle program (the VEND-RISK Study) with assessments at baseline, at the end of the lifestyle program and at 24-month follow-up.

\section{Recruitment of participants at high risk for type 2 diabetes} The Nord-Trøndelag Health Study (HUNT) is a large population-based study in Norway, with three waves of data collection. ${ }^{24}$ The present study used the third wave, the HUNT3 Survey (2006 to 2008), for its baseline risk factor assessments. In HUNT3, 5297 out of a total 48 392 individuals were identified as being at high risk of developing type 2 diabetes over the next 10 years. ${ }^{25}$ The Finnish Diabetes Risk Score (FINDRISC) questionnaire (range: 0 to 26) was used to identify individuals at high risk, where a score of 15 or more indicated at least a $30 \%$ risk of developing type 2 diabetes during the next 10 years. ${ }^{26}$ Individuals with a score of 15 or more received oral and written notes about their high risk through an invitation to attend the HUNT arm of an international multicenter study, the DE-PLAN Study (Diabetes in EuropePrevention through Lifestyle, Physical Activity and Nutrition). ${ }^{27}$

In 2012, the VEND-RISK Study was initiated in two municipalities in Nord-Trøndelag with the goal of stimulating individuals at high risk of type 2 diabetes who were overweight or obese to be more physically active and to eat a healthier diet by following the lifestyle program at the Healthy Life Centre. The individuals identified at high risk for type 2 diabetes in the HUNT3 Survey who lived in the two municipalities ( $n=332)$ were invited by letter to attend the VEND-RISK Study and then follow the lifestyle program at the Healthy Life Centre. The letter explained that they were invited because of their high risk for type 2 diabetes and that the lifestyle program aimed to motivate to lasting lifestyle change and prevent the development of type 2 diabetes. The letter also provided information about the lifestyle program at the Healthy Life Centre, with opportunity to attend individual or group-based physical activities, a group-based nutrition course, individual health conversations with health personnel and testing through physical measurements, blood samples and questionnaires. 
The Healthy Life Centres lifestyle program

Individual health conversations, based on motivational interviewing principles to promote change, ${ }^{28}$ were undertaken in the beginning and at the end of the Healthy Life Centres lifestyle program. ${ }^{8}$ The Healthy Life Centres physical activity classes and nutrition course were offered concurrently, in the same period, but on different days.

The Healthy Life Centre offered physical activity classes, as both indoor and outdoor optional activities, two to four times a week. These were either individual or group-based with physical therapists or exercise physiologists. The exercise classes had both cardio and resistance training. Participants also learnt to be familiar with walks, hiking possibilities and relevant training in the local environment. The Healthy Life Centre also provided information about activities in the local municipality after the lifestyle program period.

The Healthy Life Centre offered a group-based nutrition course; Good food for better health, which focused on eating habits and food choices based on national dietary advice. The Norwegian Directorate of Health had developed the course, which was composed of 1 hourlong sessions once a week over 10 weeks with different themes for each session. The course was both theoretical and practical, intended as a good start to achieve sustainable changes in nutrition habits. All participants received a cooking book made for the course, aiming to inspire for healthy food choices and good dietary habits. The Healthy Life Centre further informed and encouraged participants to use online nutrition programs.

Healthy Life Centre personnel consists of a physical therapist, a nutritionist and a nurse. The VEND-RISK Study participants followed the lifestyle program at Healthy Life Centres over 1 year.

\section{Measurements}

The sociodemographic characteristics included in HUNT3 and VEND-RISK were age and gender. Information about education and work participation was also obtained for HUNT DE-PLAN. Education was assessed by the question How many years of completed education do you have? and work data questions included Are you working? with the answer categories of yes and no.

The anthropometric measures included in HUNT3 and VEND-RISK were height and weight (for body mass index (BMI)) and waist circumference. Height and weight followed a standardized procedure where participants wore light clothes and no shoes. BMI was calculated as weight divided by height squared $\left(\mathrm{kg} / \mathrm{m}^{2}\right)$. Trained nurses measured waist circumference at the iliac crest at end expiration with a measuring tape. ${ }^{29}$

The FINDRISC questionnaire and fasting serum glucose were used to assess diabetes risk in HUNT3 and VEND-RISK. Hemoglobin $\mathrm{A}_{1 \mathrm{c}}\left(\mathrm{HbA}_{1 \mathrm{c}}\right)$ was also measured in VEND-RISK.

Triglycerides, total cholesterol and high-density lipoprotein (HDL) cholesterol were measured to assess cardiovascular risk factors in HUNT3 and VEND-RISK, while low-density lipoprotein (LDL) cholesterol was also measured for VEND-RISK.

The Dartmounth COOP Functional Health Assessment Charts/WONCA were used to measure physical activity for VEND-RISK with the question What was the most intense physical activity you could do for at least $2 \mathrm{~min}$ ? The fivepoint scale answers of very intense (fast running), intense (light running), moderate (fast walking), easy (regular walking) and very easy (slow walking) were dichotomized to heavy and light, where moderate was included in the light category.

The HUNT3 Survey included variables for sedentary behavior (total sitting time) and self-reported physical activity. Sedentary behavior was measured by asking About how many hours do you sit during an average day (include work hours and leisure time)? Physical activity was measured using three questions, How often do you exercise?, If you exercise as often as once or several times a week, how hard do you exercise? and How long do you exercise each time? These answers were recoded into metabolic equivalents (METs). The METs scores were divided into three different MET scores (frequency duration (METs) intensity/minutes): 1=08.3 MET-h/ wk (0500 MET-min/wk), 2=8.416.6 MET-h/wk and $3=>16.6 \mathrm{MET}-\mathrm{h} / \mathrm{wk}$. A score of 1 is below the recommendations for physical activity, while scores of 2 and 3 fulfill the recommendations for physical activity. ${ }^{30}$

Self-reported health status was measured in VEND-RISK by two COOP/WONCA Functional Health Assessment Charts questions. The first question was During the last two weeks How would you rate your health in general?, with participants answering on a five-point scale from very good to very poor. The second question was During the past twoweeks Has your physical and emotional health limited your social activities with family, friends, neighbours or groups?, with respondents answering on a five-point scale from not at all to extremely. HUNT3 obtained this information also by posing two questions. The first was How is your health at the moment?, with a four-point response scale that was subsequently dichotomized to poor and good. ${ }^{31}$ The second question was Has your physical or emotional health influenced social relations with family and friends over the last four weeks?, with answers on a five-point scale composed of not at all, a little, some, a lot and all the time. These answers were also dichotomized so that not at all was classified as no and all the other answers were classified as yes. ${ }^{32}$

In the HUNT3 Survey, all measurements were obtained at one point (20062008). The VEND-RISK Study measurements were collected at baseline (2013) and at the end of the 12-month lifestyle program (2014) and at 24-month follow-up (2015). Figure 1 shows the sample selection, time when the lifestyle program was offered and measurement points.

\section{Ethics}

The Regional Committee for Medical and Health Research Ethics in Central Norway approved the HUNT3 


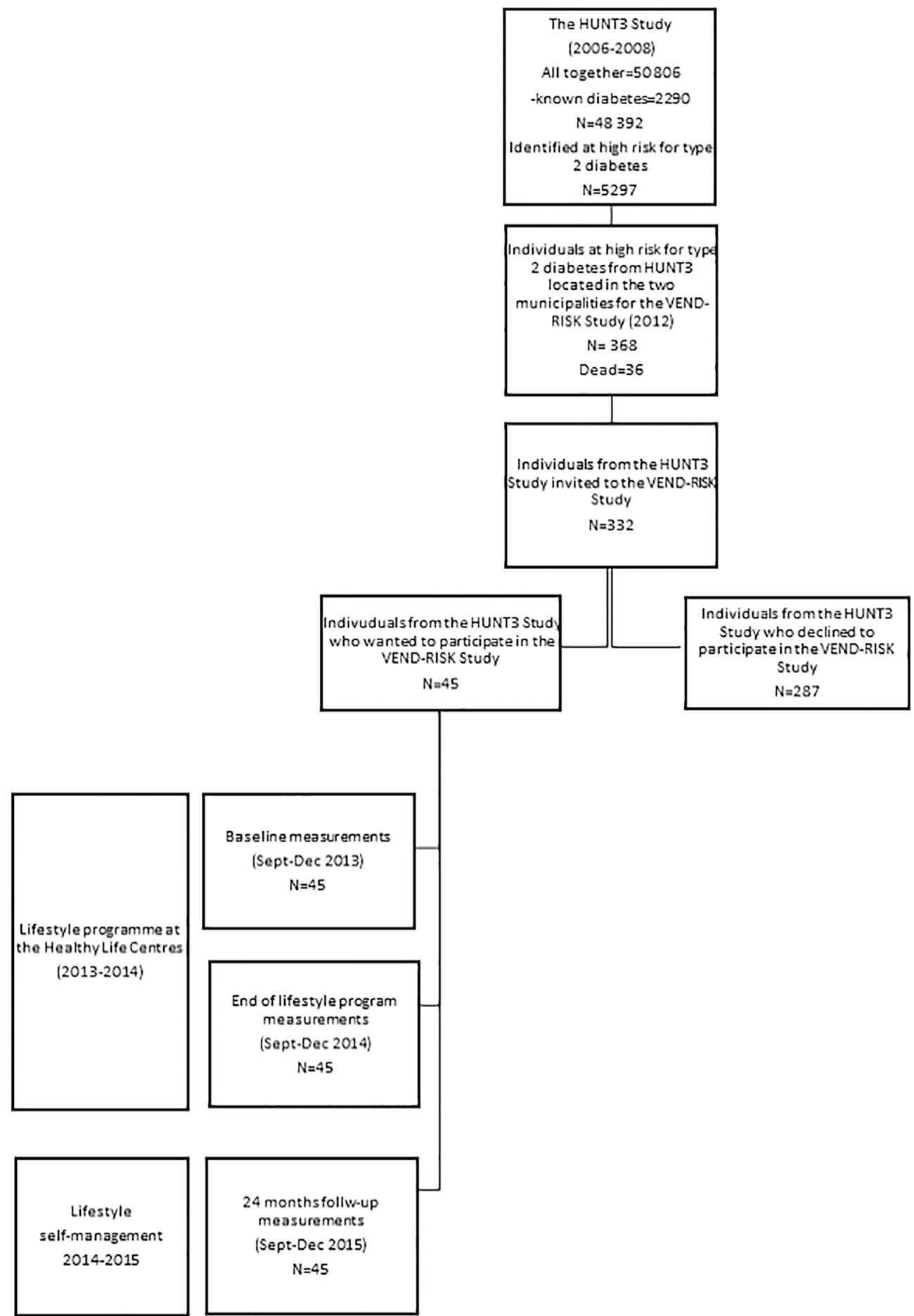

Figure 1 The studys overview from the beginning, in which individuals who were identified at high risk for type 2 diabetes at the HUNT3 Study in 2006 to 2008 and who were also located in the two municipalities for the VEND-RISK Study, were invited to participate in the lifestyle program at Healthy Life Centre in 2013.

Survey and the HUNT DE-PLAN Study, where participants received oral and written information to enable them to approve and sign an informed consent form. The Regional Committee approved the VEND-RISK study (REK nr 2010/696). Participants in the VENDRISK Study received oral and written information to enable them to approve and sign an informed consent form.

\section{Data analysis}

Datasets were analyzed using the IBM Statistical Package for Social Sciences (SPSS) V.23.0. Prior to the analyses, the data were checked for outliers and missing data. 
Variables were tested for normality by the Shapiro-Wilk test ( $p$ value above 0.05 ), and with visual inspection of histograms, normal Q-Q plots and box plots.

The HUNT3 baseline characteristics of those who accepted to participate, that is, participants, and those who declined to participate, that is, non-participants, in the VEND-RISK Study were described with meansand SD. Independent sample t-test was used to see if there were any differences between participants and non-participants. To see the changes in the main variables from baseline to the end of the 12-month lifestyle program and to the 24-month follow-up, a paired t-test was used for normally distributed variables, and Wilcoxon non-parametric test was used for non-normally distributed variables. All analyses were stratified by gender. First, for strength calculations a 5\% significance was selected with $80 \%$ strength. Afterwards, a statistical post hoc procedure $^{33}$ was used to adjust for multiple comparisons. After the adjustment, when comparing characteristics between participants and non-participants, the significance level was changed to $0.003(\alpha=0.05 / 15)$. Furthermore, when studying changes in variables for the participants from baseline to the end of the 12-month lifestyle program and to the 24-month follow-up, the significance level was changed to $0.002(\alpha=0.05 / 26)$.

\section{RESULTS}

\section{Characteristics of participants versus non-participants}

Of the 332 individuals with high risk for type 2 diabetes identified from the HUNT3 Survey (2006 to 2008) invited to the VEND-RISK Study, a total of 287 (86\%) declined to participate. Table 1 presents the characteristics of the participants and non-participants. The sociodemographic, anthropometric, diabetes risk, cardiovascular disease (CVD) and physical activity level measurements for participants were not different from the non-participating men and women. In both groups of participants and non-participants, 59\% were women with a mean age of 60 years, a mean BMI of $31 \mathrm{~kg} / \mathrm{m}^{2}$ and a mean FINDRISC score of 16.9. Both groups of participants and non-participants were at high risk for CVDs with elevated lipids. The women who declined to participate diverged significantly from women who chose to participate in that they reported fewer years of education $(p<0.001)$. For men, no differences were seen between those who declined to participate and those who participated.

\section{Participants changes at 24-month follow-up in the VEND- RISK Study}

The participants mean age at baseline in the VENDRISK Study was 64.2 years, and all of these attended the 24-month follow-up (45/45, 100\% responder rate). Table 2 presents the participants characteristics at baseline, and the mean changes in characteristics from baseline to the end of the lifestyle program and at 24-month follow-up. For the studys primary outcome,
Table 1 Characteristics (means (SD)) and comparison between participants and non-participants from the baseline HUNT3 Survey $(n=332)$

\begin{tabular}{|llll}
\hline & $\begin{array}{l}\text { Participants } \\
\text { (n=45) }\end{array}$ & $\begin{array}{l}\text { Non- } \\
\text { participants } \\
\text { (n=287) }\end{array}$ & p Value \\
\hline Variables & Means(SD) & Means(SD) & \\
\hline $\begin{array}{l}\text { Age (years) } \\
\text { Women }\end{array}$ & $58.5(9.5)$ & $60.1(9.8)$ & 0.24 \\
\hline Men & $59.5(5.8)$ & $59.5(9.3)$ & 0.99 \\
\hline FINDRISC score & & & \\
\hline Women & $16.4(1.9)$ & $16.9(2.0)$ & 0.22 \\
\hline Men & $17.2(1.9)$ & $16.9(2.3)$ & 0.65 \\
\hline Years of education & & & \\
\hline Women & $12.6(3.1)$ & $10.7(3.1)$ & $0.001^{*}$ \\
\hline Men & $12.7(3.2)$ & $11.7(3.2)$ & 0.22 \\
\hline Working & & & \\
\hline Women & $65.4 \%$ & $44.7 \%$ & 0.05 \\
\hline Men & $66.7 \%$ & $57.6 \%$ & 0.47 \\
\hline BMI (kg/m $\left.{ }^{2}\right)$ & & & \\
\hline Women & $30.6(3.8)$ & $31.0(4.4)$ & 0.65 \\
\hline Men & $31.3(3.2)$ & $31.3(3.3)$ & 0.98 \\
\hline Weight (kg) & & & \\
\hline Women & $83.5(10.6)$ & $83.5(13.5)$ & 0.99 \\
\hline Men & $100.9(12.4)$ & $98.4(11.7)$ & 0.39 \\
\hline Want circum & & & \\
\hline
\end{tabular}

Waist circumference

(cm)

$\begin{array}{llll}\text { Women } & 101.0(7.99) & 101.0(12.4) & 0.90 \\ \text { Men } & 109.0(8.2) & 108.0(8.4) & 0.59\end{array}$

\section{Triglycerides}

(mmol/L)

$\begin{array}{clll}\text { Women } & 1.8(0.9) & 1.8(1.0) & 0.77 \\ \text { Men } & 2.0(1.1) & 2.2(1.2) & 0.47\end{array}$

Total cholesterol

(mmol/L)

$\begin{array}{llll}\text { Women } & 6.0(1.2) & 5.8(1.0) & 0.28 \\ \text { Men } & 5.4(1.1) & 5.5(1.1) & 0.68\end{array}$

HDL cholesterol ( $\mathrm{mmol} / \mathrm{L}$ )

$\begin{array}{llll}\text { Women } & 1.4(0.4) & 1.4(0.4) & 0.91 \\ \text { Men } & 1.1(0.3) & 1.2(0.3) & 0.37\end{array}$

Serum glucose (mmol/L)

$\begin{array}{llll}\text { Women } & 5.5(0.7) & 5.8(1.3) & 0.27 \\ \text { Men } & 5.9(1.1) & 6.2(1.8) & 0.57\end{array}$

Sitting time (hours a day)

\begin{tabular}{lccc} 
Women & $6.2(3.7)$ & $5.9(2.7)$ & 0.68 \\
Men & $6.2(3.5)$ & $6.1(3.0)$ & 0.87 \\
\hline
\end{tabular}




\begin{tabular}{|c|c|c|c|}
\hline & $\begin{array}{l}\text { Participants } \\
(n=45)\end{array}$ & $\begin{array}{l}\text { Non- } \\
\text { participants } \\
(\mathbf{n}=287)\end{array}$ & p Value \\
\hline \multicolumn{4}{|c|}{$\begin{array}{l}\text { Physical activity } \\
\text { (hours/week) }\end{array}$} \\
\hline Women & $5.8(3.4)$ & $5.4(4.4)$ & 0.70 \\
\hline Men & $6.5(5.4)$ & $6.6(5.4)$ & 0.90 \\
\hline \multicolumn{4}{|c|}{$\begin{array}{l}\text { Self-perceived health } \\
\text { (Subjective Well- } \\
\text { Being) Good }\end{array}$} \\
\hline Women & $65.4 \%$ & $57.6 \%$ & 0.47 \\
\hline Men & $61.1 \%$ & $64.4 \%$ & 0.91 \\
\hline \multicolumn{4}{|c|}{$\begin{array}{l}\text { Physical or emotional } \\
\text { health impacts on } \\
\text { social relations the } \\
\text { last } 14 \text { days }\end{array}$} \\
\hline Women & $19.2 \%$ & $40.6 \%$ & 0.04 \\
\hline Men & $22.2 \%$ & $28.0 \%$ & 0.57 \\
\hline
\end{tabular}

*Significant $\mathrm{p}<0.003$.

BMI, body mass index; FINDRISC, Finnish Diabetes Risk Score; HDL, high-density lipoprotein.

in the total sample, none developed type 2 diabetes at 24-month follow-up, and $\mathrm{HbA}_{1 \mathrm{c}}$ decreased significantly $(-0.2 \mathrm{mmol} / \mathrm{L})$ for both women and men. For the secondary outcome, the mean BMI changed slightly, but not significantly, from $30.2 \mathrm{~kg} / \mathrm{m}^{2}$ at baseline to $29.7 \mathrm{~kg}$ / $\mathrm{m}^{2}$ in the total sample. Furthermore, waist circumference in women showed a significant decrease of $4 \mathrm{~cm}$ from baseline to 24-month follow-up $(\mathrm{p}<0.001)$. There were no changes in the self-reported physical activity level or health status (COOP/WONCA) at the end of the lifestyle program or at 24-month follow-up.

\section{CONCLUSIONS}

In this study, of all those who were identified as being at high risk for type 2 diabetes in the HUNT3 Survey and were invited to the 12-month Healthy Life Centre lifestyle program (the VEND-RISK Study), a total of $86 \%$ (287/332) declined to participate. Women who declined to participate had fewer years of education. The primary outcome among all participants at 24-month follow-up in the VEND-RISK Study was none developed type 2 diabetes, and $\mathrm{HbA}_{1 \mathrm{c}}$ decreased significantly for both women and men. The secondary outcome was BMI decreased slightly among all participants, and for women, waist circumference decreased significantly.

In the present study, non-participating women had fewer years of education. Low educational attainment is known to have a negative impact on health. ${ }^{34}$ Much as in our study, non-participants in other studies are reported to have lower educational attainment. ${ }^{35}$ However, several individual factors can explain non-participation in lifestyle programs, broadly clustered as social, psychological and logistical barriers, ${ }^{36}$ and previous negative experiences. ${ }^{37}$ Awareness of ones own unhealthy lifestyle, perception of susceptibility of disease and motivation to make lifestyle changes have been found to be associated with participation in lifestyle programs. ${ }^{38}$ Women tend to be more concerned about their health and use the healthcare more often than men. ${ }^{17}$ Even so, previous studies have questioned whether individuals with unhealthy lifestyle are less likely to participate in primary healthcare interventions than those in better health. ${ }^{39}$ Some individuals at high risk for type 2 diabetes with low educational attainment may not understand the importance of how lifestyle affects their risk for type 2 diabetes. Previous findings have showed that concerns about family history of diabetes was more important for lifestyle change than how lifestyle affected the risk for type 2 diabetes. ${ }^{40}$ Women are found to recall a family history of diabetes better than men. ${ }^{41}$ This could explain the effect modification in gender for participants and non-participants concerning educational attainment.

\section{Follow-up of participants in the lifestyle program}

A qualitative study that explored a smaller segment of this studys sample found that the participants already saw themselves as active, ${ }^{40}$ coining with this study results from the self-reported physical activity level. Another study found those who increased their physical activity in a lifestyle program reduced their weight and waist circumference, along with fasting glucose compared with those who did not increase their physical activity. ${ }^{42}$ There could be other factors explaining change in weight, waist circumference and diabetes risk status other than physical activity level. As in the present study, $\mathrm{HbA}_{1 \mathrm{c}}$ decreased significantly for all participants, and waist circumference decreased significantly for women despite no change in physical activity level. However, with an intensive program of lifestyle modification like in the DPP Study, older adults achieved more success at preventing type 2 diabetes and reducing weight (5).

Participants at high risk for type 2 diabetes in this study were older adults who slightly decreased their mean BMI from 30.2 at baseline to $29.7 \mathrm{~kg} / \mathrm{m}^{2}$ at 24 -month follow-up. The higher age of individuals at risk for type 2 diabetes has been found to be associated with lower expectations and lower clarity regarding lifestyle changes. ${ }^{43}$ People at high risk for type 2 diabetes are older compared with people who are not at risk for type 2 diabetes. ${ }^{44}$ However, a BMI range of $23.029 .9 \mathrm{~kg} / \mathrm{m}^{2}$ is associated with optimal longevity for older adults. ${ }^{45}$ Other studies have found that being older, inactive and obese are independent risk factors for metabolic changes leading to impaired glucose intolerance. ${ }^{47}{ }^{48}$ Obesity is found to be associated with higher mortality across all ages but not in older adults. ${ }^{45}$ The small changes observed in the present study in the BMIs of participants, but significant reduction in $\mathrm{HbA}_{1 \mathrm{c}}$ for all participants and in waist circumference for women should be interpreted as positive, especially regarding maintaining and improving the reduction,. 
Table 2 Participants characteristics at the VEND-RISK Study baseline measurements (meansSD) and participants changes from baseline to the end of lifestyle program (meansSD) and to 24-month follow-up (meansSD).

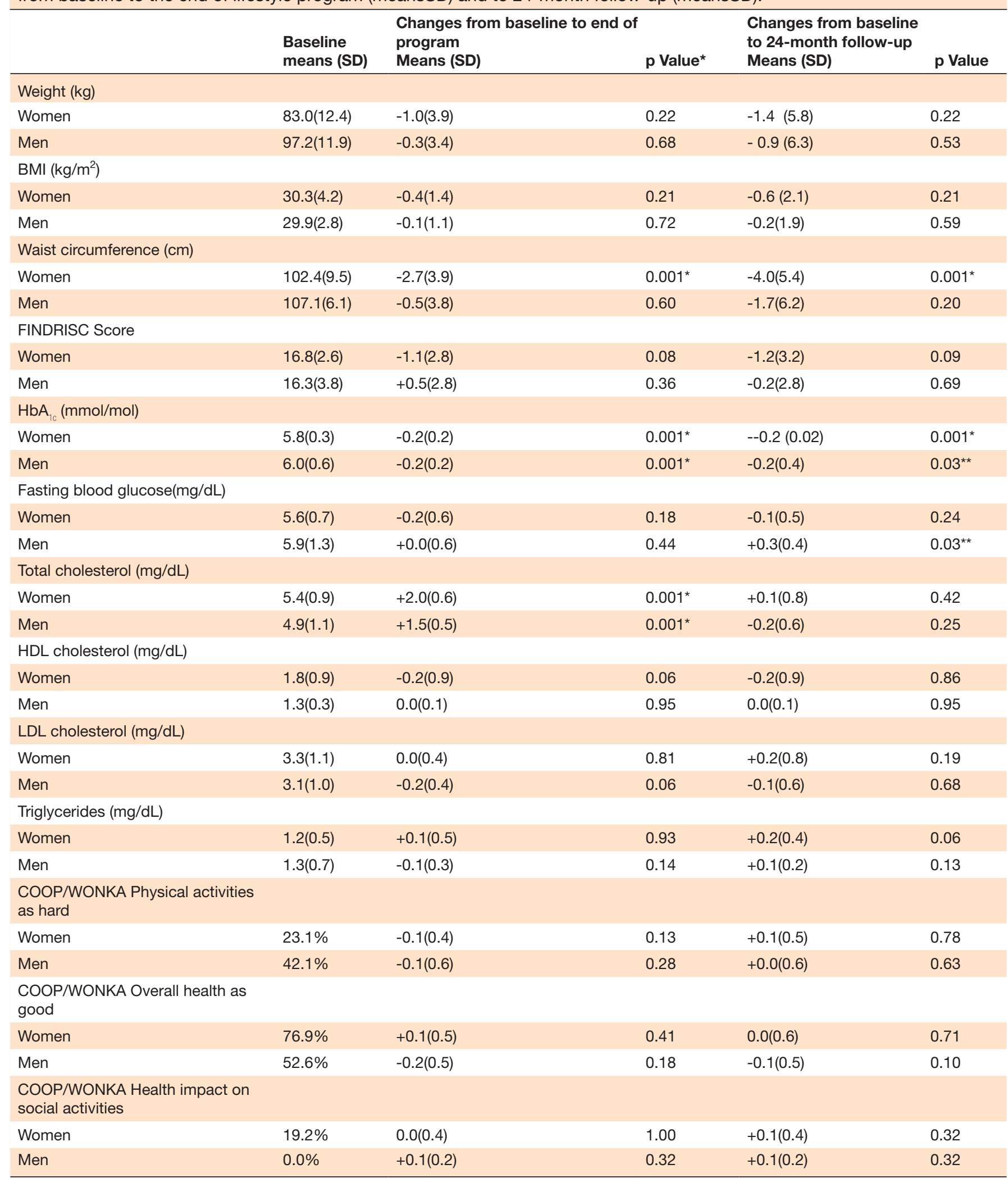

** Significant $p<0.05$.

${ }^{*}$ Significant $p<0.002$.

Wilcoxon test used.

BMI, body mass index; FINDRISC, Finnish Diabetes Risk Score; HDL, high-density lipoprotein.

Thus, the primary aim of the VEND-RISK Study was to prevent type 2 diabetes and the further development of 
overweight and obesity in participants.

Furthermore, we found the improvements in the participating women cardiometabolic changes to be maintained at 24-month follow-up and improving further after completion of the 12-month program. The maintenance of changes is often discussed as one of the greatest challenges in lifestyle treatment of overweight/obesity and its metabolic complications. ${ }^{49}$ However, in order to maintain lifestyle change the surrounding environment can facilitate the outcome for the person trying to maintain the changes. ${ }^{50}$ The qualitative study that explored a segment of the same sample used in this study found that participants highlighted their surrounding resources as important to maintain healthy habits. ${ }^{40}$

In light of our previous findings, ${ }^{37} 40$ there may be a gap between the participants from the HUNT3 Survey presented in this study and those referred to lifestyle programs in the primary healthcare in Norway, in that the latter individuals may often already have developed different diseases related to their lifestyle choices. The previous and present results raise questions as to who benefits from lifestyle programs and highlight the importance of prevention programs at a population-based level, such as health promotion strategies that target all individuals.

\section{Strengths and limitations}

The cross-sectional design used to describe non-participants and participants allows us to compare the two groups, but is limited in its ability to elucidate causal relationships. Follow-up data of health measurements of the non-participants could be obtained in the next HUNT Survey (HUNT4) in 2017 to 2019. However, those participating in the HUNT3 Survey may differ from those in the general population who did not participate in the HUNT3 Survey at all.

There are few studies that evaluate the long-term effects of lifestyle programs similar to those applied by the Norwegian Healthy Life Centre for more than 3 months after programs have ended. ${ }^{51}$ We believe that having 24-month follow-up data is a strength. The VEND-RISK Study was undertaken through a lifestyle program at the Healthy Life Centre in a Norwegian primary healthcare setting. There was no control group for the follow-up. Participants who are randomized against their will to treatment that solely involves lifestyle change may result in very low compliance. The lack of a control group weakens the generalizability of our findings, and can be a systematic bias, especially regarding motivation for the sample.

A limitation of the study is the relatively small number of participants and the resulting low statistical power. The significance level was lowered due to multiple comparisons to reduce the possibility of finding a statistical difference by chance. Even so, making adjustments for multiple comparisons may lead to more errors of interpretation when the data under evaluation are actual observations on nature, like in our study. ${ }^{52}$ There were fewer men than women in our study. Thus, the statistical power in the sex-stratified analyses were even lower for men than for women, which may partly explain the lack of statistically significant differences among men for some of our study outcomes .

The present study contributes to knowledge about lifestyle programs in the Norwegian primary healthcare system, a venue that must take active steps to prevent the development of type 2 diabetes in the population. The study suggests that women with low education in Norway should be targeted in primary healthcare settings for recruitment to programs to prevent type 2 diabetes.

\section{Author affiliations}

${ }^{1}$ Department of Health Sciences and Nursing, Nord University, Levanger, Norway ${ }^{2}$ Department of Public Health and Nursing, Faculty of Medicine and Health Sciences, Norwegian University of Science and Technology, Trondheim, Norway ${ }^{3}$ Centre for Obesity Research, Clinic of Surgery, St. Olavs University Hospital, Trondheim, Norway

${ }^{4}$ Department of Cancer Research and Molecular Medicine, Faculty of Medicine and Health Sciences, Norwegian University of Science and Technology, Trondheim, Norway

${ }^{5}$ Department of Community Health and General Practice, Faculty of Medicine and Health Sciences, HUNT Research Centre, Norwegian University of Science and Technology, Trondheim, Norway

${ }^{6}$ Norwegian National Advisory Unit for Aging and Health, Vestfold Health Trust, Tønsberg, Norway

${ }^{7}$ St. Olavs University Hospital, Trondheim, Norway

Contributors BK planned and was responsible for the VEND-RISK Study. KM conducted and organized the HUNT DE-PLAN Study. ISF, BK and A-SH designed the present study together with KM and VR. ISF analyzed the data and interpreted the results, together with A-SH and BK. ISF drafted the manuscript with comments from A-SH, BK and VR. All authors read the final manuscript.

Funding Nord University, Levanger, Norway, funded this research.

Competing interests None declared.

Patient consent Obtained.

Ethics approval The Regional Committees for Medical and Health Research Ethics (REK), Norway (REK nr 2010/696) approved the study.

Provenance and peer review Not commissioned; externally peer reviewed. Data sharing statement The unpublished data from the current study are not publicly available due to secure the anonymity of the participants, but datasets are available from the corresponding author on reasonable request and with permission of The Regional Committee for Medical and Health Research Ethics in Central Norway. The Regional Committee for Medical and Health Research Ethics in Central Norway has not given access to datasets to others than the authors. Restrictions therefore apply to the availability of these data.

Open Access This is an Open Access article distributed in accordance with the Creative Commons Attribution Non Commercial (CC BY-NC 4.0) license, which permits others to distribute, remix, adapt, build upon this work non-commercially, and license their derivative works on different terms, provided the original work is properly cited and the use is non-commercial. See: http://creativecommons.org/ licenses/by-nc/4.0/

C Article author(s) (or their employer(s) unless otherwise stated in the text of the article) 2017. All rights reserved. No commercial use is permitted unless otherwise expressly granted.

\section{REFERENCES}

1. World Health Organisation. Global status report on noncommunicable diseases: Geneva, 2014.

2. Midthjell K, Krüger O, Holmen J, et al. Rapid changes in the prevalence of obesity and known diabetes in an adult norwegian population. the Nord-Trøndelag Health surveys: 1984-1986 and 1995-1997. Diabetes Care 1999;22:1813.20. 
3. World Health Organization. Global action plan for the prevention and control of NCDs 2013-2020. Geneva, 2013.

4. Tuomilehto J, Lindstrm J, Eriksson JG, et al. Finnish Diabetes Prevention Study Group, Prevention of type 2 Diabetes Mellitus by changes in lifestyle among subjects with impaired glucose tolerance. N Engl J Med 2001;344:1343.50.

5. Knowler WC, Barrett-Connor E, Fowler SE, et al. Diabetes Prevention Program Research Group. Reduction in the incidence of type 2 diabetes with lifestyle intervention or metformin. N Engl J Med 2002;346:393.403

6. Li G, Zhang P, Wang J, et al. The long-term effect of lifestyle interventions to prevent diabetes in the China da Qing Diabetes Prevention Study: a 20-year follow-up study. The Lancet 2008:371:1783.9.

7. The Norwegian Directorate of Health. National Instruction Manual for Municipal Healhty Life Centre - Establishment and organization. Oslo, 2016. https://helsedirektoratet.no/Lists/ Publikasjoner/Attachments/53/Veileder\%20for\%20kommunale\% 20frisklivssentraler_IS1896.pdf. (Cited 14 Oct 2016).

8. The Norwegian Ministry of Health and Care Services, Meld. St. 16 20102011. Oslo: National Health Care Plan (2011-2015), 2011. https://www.regjeringen.no/no/dokumenter/meld-st-16-20102011/ id639794/sec1. (Cited 10 Apr 2016).

9. Kong W, Langlois MF, Kamga-Ngand C, et al. Predictors of success to weight-loss intervention program in individuals at high risk for type 2 diabetes. Diabetes Res Clin Pract 2010;90:147.53.

10. Gesche J, Renault K, Nrgaard K, et al. Representativeness of participants in a lifestyle intervention study in obese pregnant women - the difference between study participants and nonparticipants. Obes Facts 2014;7:351.60.

11. Groeneveld IF, Proper KI, van der Beek AJ, et al. Factors associated with non-participation and drop-out in a lifestyle intervention for workers with an elevated risk of cardiovascular disease. Int J Behav Nutr Phys Act 2009;6:80.

12. Boshuizen HC, Viet AL, Picavet HS, et al. Non-response in a survey of cardiovascular risk factors in the dutch population: determinants and resulting biases. Public Health 2006;120:297.308.

13. Chinn DJ, White M, Howel D, et al. Factors associated with nonparticipation in a physical activity promotion trial. Public Health 2006;120:309.19.

14. Lerman Y, Shemer J. Epidemiologic characteristics of participants and nonparticipants in health-promotion programs. J Occup Environ Med 1996;38:535.8.

15. Lakerveld J, IJzelenberg W, van Tulder MW, et al. Motives for (not) participating in a lifestyle intervention trial. BMC Med Res Methodol 2008;8:17

16. Hansen E, Fonager K, Freund KS, et al. The impact of nonresponders on health and lifestyle outcomes in an intervention study. BMC Res Notes 2014;7:632.

17. Bertakis KD, Azari R, Helms LJ, et al. Gender differences in the utilization of health care services. J Fam Pract 2000:49:147.52

18. Narayan KM, Boyle JP, Thompson TJ, et al. Lifetime risk for diabetes mellitus in the United States. JAMA 2003;290:1884.90.

19. Saaristo T, Moilanen L, Korpi-Hyvlti E, et al. Lifestyle intervention for prevention of type 2 diabetes in primary health care: one-year follow-up of the finnish National Diabetes Prevention Program (FIND2D). Diabetes Care 2010;33:2146.51.

20. Vermunt PWA, Milder IEJ, Wielaard F, et al. Lifestyle counseling for type 2 Diabetes risk reduction in dutch primary care. Diabetes care 2011;34:919.25.

21. Walker C, Hernan A, Reddy P, et al. Sustaining modified behaviours learnt in a diabetes prevention program in regional Australia: the role of social context. BMC Health Serv Res 2012;12.

22. Qiao Q, Pang Z, Gao W, et al. A large-scale diabetes prevention program in real-life settings in Qingdao of China (2006-2012). Prim Care Diabetes 2010;4:99.103.

23. Cardona-Morrell M, Rychetnik L, Morrell SL, et al. Reduction of diabetes risk in routine clinical practice: are physical activity and nutrition interventions feasible and are the outcomes from reference trials replicable? A systematic review and meta-analysis. BMC Public Health 2010;29:653.

24. Krokstad S, Langhammer A, Hveem K, et al. Cohort Profile: the HUNT Study, Norway. Int J Epidemiol 2013;42:968.77.

25. Jølle A, Midthjell K, Holmen J, et al. Impact of sex and age on the performance of FINDRISC: the HUNT Study in Norway. BMJ Open Diabetes Res Care 2016;4:e000217.

26. Lindstrm J, Tuomilehto J. The diabetes risk score: a practical tool to predict type 2 diabetes risk. Diabetes Care 2003;26:725.31.

27. Schwarz PE, Lindstrøm J, Kissimova-Scarbeck K, et al. DE-PLAN project. The european perspective of type 2 diabetes prevention: diabetes in Europe--prevention using lifestyle, physical activity and nutritional intervention (DE-PLAN) project. Exp Clin Endocrinol Diabetes 2008:116:167.72.

28. Rollnick S, Butler CC, Kinnersley P, et al. Motivational interviewing. BMJ 2010;340:c1900.

29. Siren R, Eriksson JG, Vanhanen H. Waist circumference a good indicator of future risk for type 2 diabetes and cardiovascular disease. BMC Public Health 2012;12:631.

30. Physical activity guidelines Advisory Committee, Physical Activity guidelines Advisory Committee Report. Washington DC: Editor: Department of Health and Human Services, 2008. https://health.gov/ paguidelines/report/pdf/committeereport.pdf. (Cited 13 Jul 2016).

31. Krokstad S, Knutsen MS. Public health development - the Health Study in Nord Trndelag HUNT 1 (1984-86), HUNT 2 (1995-97), HUNT 3 (2006-08). HUNT Research Centre/NTNU 2011:113.7.

32. Ware JE, Kosinksi M, Dewey JE, et al. How to score and interpret single-item health status measures: a manual for users of the SF-8 health survey. Quality Metric Incorporated: Lincoln, RI, 2001.

33. Bender R, Lange S. Adjusting for multiple testing--when and how? $J$ Clin Epidemiol 2001;54:343.9.

34. Huisman M, Kunst AE, Bopp M, et al. Educational inequalities in cause-specific mortality in middle-aged and older men and women in eight western European populations. Lancet 2005;365:493.500.

35. Lakerveld J, lizelenberg W, van Tulder MW, et al. Motives for (not) participating in a lifestyle intervention trial. BMC Med Res Methodol 2008;8(17-10):17.

36. Murray J, Craigs CL, Hill KM, et al. A systematic review of patient reported factors associated with uptake and completion of cardiovascular lifestyle behaviour change. BMC Cardiovasc Disord 2012;12:120.

37. Flling IS, Solbjr M, Helvik AS. Previous experiences and emotional baggage as barriers to lifestyle change - a qualitative study of norwegian healthy Life Centre participants. BMC Fam Pract 2015;16:73.

38. Toft UN, Kristoffersen LH, Aadahl M, et al. Diet and exercise intervention in a general population--mediators of participation and adherence: the Inter99 study. Eur J Public Health 2007;17:455.63.

39. Feng X, Girosi F, McRae IS. People with multiple unhealthy lifestyles are less likely to consult primary healthcare. BMC Fam Pract 2014:15:126.

40. Flling IS, Solbjr M, Midthjell K, et al. Exploring lifestyle and risk in preventing type 2 diabetes-a nested qualitative study of older participants in a lifestyle intervention program (VEND-RISK). BMC Public Health 2016;16:876.

41. Fuentes A, Desrocher M. The effects of gender on the retrieval of episodic and semantic components of autobiographical memory. Memory 2013;21:619.32.

42. Kujala UM, Jokelainen $\mathrm{J}$, Oksa $\mathrm{H}$, et al. Increase in physical activity and cardiometabolic risk profile change during lifestyle intervention in primary healthcare: 1-year follow-up study among individuals at high risk for type 2 diabetes. BMJ Open 2011:1:e000292.

43. Bouchard DR, Langlois MF, Domingue M, et al. Age differences in expectations and readiness regarding lifestyle modifications in individuals at high risk of diabetes. Arch Phys Med Rehabil 2012;93:1059.64

44. Graham E, Garipy G, Burns RJ, et al. Demographic, lifestyle, and health characteristics of older adults with prediabetes in England. Prev Med 2015;77:74.9.

45. Flegal KM, Kit BK, Graubard BI. Overweight, obesity, and all-cause mortality--reply. JAMA 2013;309:1681.2.

46. Winter JE, Maclnnis RJ, Wattanapenpaiboon N, et al. BMI and all-cause mortality in older adults: a meta-analysis. Am J Clin Nutr 2014;99:875.90.

47. Dey DK, Lissner L. Obesity in 70-year-old subjects as a risk factor for 15-year coronary heart disease incidence. Obes Res 2003;11:817.27.

48. Fagot-Campagna A, Bourdel-Marchasson I, Simon D, et al. Burden of diabetes in an aging population: prevalence, incidence, mortality, characteristics and quality of care. Diabetes Metab 2005;315S(Spec No 2):5S3552.5.

49. Jeffery RW, Drewnowski A, Epstein LH, et al. Long-term maintenance of weight loss: current status. Health Psychol 2000;19:5.16.

50. Elfhag K, Rssner S. Who succeeds in maintaining weight loss? A conceptual review of factors associated with weight loss maintenance and weight regain. Obes Rev 2005;6:67.85.

51. Denison E, Vist GE, Underland V, et al. Effects of organised lifestyle intervention programs targeting behaviors that increase the risk of illness in adults, a systematic review. Oslo: Editor: The Norwegian Knowledge Centre for the Health Services, 2012. http:// www.kunnskapssenteret.no/publikasjoner/effekter-av-organisert- 
oppfolging-pa-atferd-som-oker-risiko-for-sykdom-hos-voksne. (Cited 02 Feb 2016).
52. Drachman D. Adjusting for multiple comparisons. Journal of Clinical Research Best Practice 2012;8. 